\title{
A new lever reduction technique for the surgical treatment of elderly patients with lumbar degenerative Spondylolisthesis
}

\author{
Chao Kong ${ }^{\dagger}$, Wei Wang ${ }^{\dagger}$, Xiangyu Li, Xiangyao Sun, Junzhe Ding and Shibao Lu*
}

\begin{abstract}
Background: Proper reduction method for Lumbar degenerative spondylolisthesis (LDS) is still controversial. The aim of this study was to determine the safety and effectiveness of lever reduction combined with traditional elevating-pull reduction technique for the treatment of elderly patients with LDS.

Methods: From May 2015 to December 2017, 142 elderly patients ( $\geq 65$ years) diagnosed with LDS were enrolled in this study with a mean follow-up of $25.42 \pm 8.31$ months. All patients were operated using lever reduction combined with traditional elevating-pull reduction technique. Patient age, sex, body mass index, bone mineral density, preoperative comorbidities, surgical duration, blood loss, and surgical complications were collected form patient charts. Clinical data as visual analog scale (VAS), Oswestry Disability Index (ODI), and 36-Item Short Form Health Survey (SF-36) were collected preoperatively, 1 month postoperatively, and at the final follow-up. Radiographic evaluation included slip percentage, slip angle (SA), lumbar lordosis (LL), and fusion status.
\end{abstract}

Results: The clinical parameters of VAS back, VAS leg, ODI, and SF-36 had significantly improved at both followups after surgery. A significant improvement was indicated for slippage reduction at both follow-ups, showing no significant correction loss after surgery. SA significantly increased after surgery and was well maintained at the final follow-up. LL was not affected by the surgery. At the final follow-up, complete fusion was obtained in 121 patients (85.2\%) and partial fusion in 21 (14.8\%). Revision surgery was performed for one patient. Screw loosening was observed in $3(2.11 \%)$ cases. No nerve root injury or adjacent segment disease was observed.

Conclusions: This new lever reduction combined with traditional elevating-pull reduction technique for the surgical treatment of elderly patients with LDS is both safe and effective. Satisfactory correction and fusion rates were achieved with acceptable correction loss and reduction-related complications.

Keywords: Lumbar degenerative spondylolisthesis, Elderly, Reduction method, Lever reduction, Level of Evidence: IV.

\section{Background}

Lumbar degenerative spondylolisthesis (LDS) is a common spinal degenerative disorder that can cause low back pain and radiculopathy if combined with lumbar stenosis [1-3]. According to the classification proposed by Meyerding [4], LDS often causes low-grade slippage (grades 1 and 2) due to an intact neural arch. For most

\footnotetext{
* Correspondence: spinelu@163.com

${ }^{\dagger}$ Chao Kong and Wei Wang are co-first authors.

Department of Orthopedics, Beijing Xuanwu Hospital, Capital Medical

University, Beijing 100053, China
}

patients with LDS, conservative treatments as physical therapy, medication, lifestyle management, and multidisciplinary pain management are effective $[5,6]$. Surgical approaches are prompted in some refractory cases to achieve greater pain relief and functional improvement after mid-term follow-up $[7,8]$. The aim of surgery includes decompression of neural encroachment and stabilization of the spinal column. Despite the large number of published studies, there is no consensus on the most appropriate surgical method $[9,10]$. Most of 
the debate revolves around whether reduction should be performed and to which extent.

Many surgeons favor "in situ" fusion, which is the most common treatment method for LDS [11, 12]. However, in situ fusion is associated with the potential risks of pseudarthrosis and slippage progression, and is insufficient to restore lumbar lordosis [9]. To improve the fusion rates and restore sagittal alignment, instrumentation reduction is recommended for some patients. However, instrumentation reduction may cause screw loosening and loss of reduction, especially in elderly patients with osteoporosis $[13,14]$.

Traditional reduction methods mainly rely on distraction of the disc space and direct elevating-pull of the pedicle screws to obtain satisfactory reduction. But, in osteoporosis patients, poor bone quality may lead to inadequate bone-screw contact forces and, thus, more implant-related complications. Lian et al. $[15,16]$ reported three cases in which the pedicle screws in the slipped vertebra were pulled out during intraoperative reduction. However, it remains controversial whether reduction of elderly LDS patients with low bone mineral density (BMD) should be avoided [17].

To reduce the surgical related complications caused by reduction, we adopted a new lever reduction technique combined with traditional elevating-pull reduction technique during the reduction of elderly LDS patients in March 2014. Therefore, the aim of the present study was to evaluate the safety and effectiveness of this lever reduction technique for the treatment of elderly LDS patients.

\section{Methods}

\section{Patient demographics}

The study cohort prospectively included a total of 148 elderly patients (age, $\geq 65$ years) diagnosed with LDS from May 2015 to December 2017 who met the following inclusion criteria: 1) a diagnosis of LDS and symptomatic lumbar spinal stenosis; 2) unresponsive to conservative treatments for more than 3 months; 3 ) instability of flexion and extension, as determined by $\mathrm{X}$ ray; and 4) availability of at least 12 months of follow-up data. Patients with pars defects, hip disorders, previous spinal surgery or trauma, or incomplete data, were excluded from analysis.

Demographic and clinical data, including age, sex, body mass index, BMD, preoperative comorbidities, surgical duration, blood loss, and surgical complications were collected from electronic charts. The World Health Organization defines normal BMD as a T-score greater than - 1.0. Low bone mass or osteopenia is defined as 1.0 to -2.5 , whereas $\mathrm{T}$-scores equal to or less than -2.5 indicate osteoporosis [18].
The visual analog scale (VAS), Oswestry Disability Index (ODI), and 36-Item Short Form Health Survey (SF-36) were used to measure outcomes. Clinical data were collected before surgery, 1 month postoperatively, and at the final follow-up. Preoperative lumbar radiographs (standing anteroposterior and lateral, flexion, and extension views), computed tomography, and magnetic resonance imaging were obtained from all patients.

\section{Radiological assessment}

Plain radiographs were obtained preoperatively, 1 month postoperatively, and at the last follow-up. Preoperative and postoperative radiographic evaluation included slip percentage (SP), slip angle (SA), and lumbar lordosis (LL). Vertebral SP was measured as the percentage of slippage in relation to the lower vertebral body length, according to the Taillard technique [19] and graded according to the Meyerding classification [20]. SA was defined as the angle between the lower end plate of the slipped vertebrae and upper end plate of the lower vertebrae. Positive values were used to denote lordosis. LL was defined as the Cobb angle between the upper L1 end plate and upper $\mathrm{S} 1$ end plate. The reduction rate was calculated as: reduction rate $(\%)=$ (preoperativepostoperative SP) * 100/preoperative SP. All measurements were performed and repeated by two blinded observers.

Fusion was assessed on post-operative computed tomographic images obtained at the final follow-up according to the classification of Tan et al. [21] (Table 1). Pedicle screw loosening was viewed as any pedicular cortical breach or directional change [22].

\section{Surgical technique}

All surgeries were performed through an open posterior midline approach. Before bony decompression, bilateral pedicle screws were placed. Decompression consisted of

Table 1 CT-based Classification of Spinal Fusion

\begin{tabular}{|c|c|c|}
\hline Grades & Description & Criteria \\
\hline $\begin{array}{l}\text { Grade } \\
\text { । }\end{array}$ & $\begin{array}{l}\text { Complete } \\
\text { fusion }\end{array}$ & $\begin{array}{l}\text { Cortical union of the allograft at bone cranial } \\
\text { and caudal ends and continuity of trabecular } \\
\text { pattern between the autograft within the } \\
\text { medullary canal of the allograft and the } \\
\text { adjacent cranial and caudal vertebral bodies }\end{array}$ \\
\hline $\begin{array}{l}\text { Grade } \\
\|\end{array}$ & Partial fusion & $\begin{array}{l}\text { Cortical union of the allograft to the } \\
\text { endplates at each end however with partial or } \\
\text { absent trabecular continuity between the } \\
\text { medullary autograft and the adjacent } \\
\text { vertebral body bone at one or either end. }\end{array}$ \\
\hline $\begin{array}{l}\text { Grade } \\
\text { III }\end{array}$ & $\begin{array}{l}\text { Unipolar } \\
\text { pseudarthrosis }\end{array}$ & $\begin{array}{l}\text { Cranial or caudal cortical nonunion of the } \\
\text { allograft with associated central trabecular } \\
\text { discontinuity }\end{array}$ \\
\hline $\begin{array}{l}\text { Grade } \\
\text { IV }\end{array}$ & $\begin{array}{l}\text { Bipolar } \\
\text { pseudarthrosis }\end{array}$ & $\begin{array}{l}\text { Both superior and inferior cortical nonunion } \\
\text { with a complete lack of central trabecular } \\
\text { continuity }\end{array}$ \\
\hline
\end{tabular}


bilateral facetectomy and partial foraminotomy, including the hypertrophic ligament flavum. The disc space was opened and thoroughly cleaned with intradiscal drills and pituitary rongeurs. The cartilaginous endplates were cleaned with caution so as to not cause injury to the bone endplates. Bilateral nerve roots were liberated before reduction. An independently developed reduction facility was used during the surgery (Fig. 1). The reduction process consisted of five steps (Fig. 2): 1) placement of pedicle screws at both vertebra of the slipped levels; 2) decompression of the nerve roots before reduction (after removal of the disk tissues and endplate preparation, a rod was placed unilaterally and the pedicle screw of the lower vertebrae was locked); 3) placement of a lever repositioner at the anterior rim of the slipped vertebrae under fluoroscopy; 4) with the lower vertebrae as a lever fulcrum, force was applied to gradually pry the slipped vertebrae upward; and 5) during the lever reduction process, lock the pedicle screws of the slipped vertebrae. Then, an additional rod was placed and all screws were locked. The extent of slip reduction was verified with fluoroscopy (Fig. 3). After reduction, the interspace was packed with autologous bone graft material and an appropriate cage filled with bone was inserted into the disc space. During reduction, no distraction was used.

\section{Statistical analysis}

All statistical analyses were performed using PASW Statistics for Windows, version 18.0 (SPSS Inc., Chicago, IL, USA). Continuous data are presented as the mean \pm standard deviation (SD). The Kolmogorov-Smirnov test was used to determine whether the variables were normally distributed. One-way analysis of variance was used to identify differences among the clinical and radiological parameters at different time points. A probability $(p)$ value of $<0.05$ was considered statistically significant.

\section{Results}

\section{Study population}

A total of 142 elderly patients who underwent surgery in our institute for a diagnosis of LDS were followed for a mean of $25.42 \pm 8.31$ (range, 14-41) months. Six patients who lived in other cities and were unwilling to travel were lost to follow-up. The demographic data and intraoperative characteristics of all patients are shown in Table 2. The mean BMD was $0.821 \pm 0.164 \mathrm{~g} / \mathrm{cm}^{2}$. The T-scores > -1.0 (normal BMD) were in $34(23.9 \%)$ patients, between -1 and -2.5 (osteopenia) in 79 (55.6\%), and less than -2.5 (osteoporosis) in 29 (20.4\%).

The distribution of slipped levels was: L2/3 in 2 cases, L3/4 in $18, L 4 / 5$ in 89 , and L5/S1 in 38. Five patients had two slipped levels (L3/4 and L4/5 in 4 cases, L4/5 and L5/S1 in 1 case). According to the preoperative Meyerding classification, 98 patients had grade I $(0 \%<$

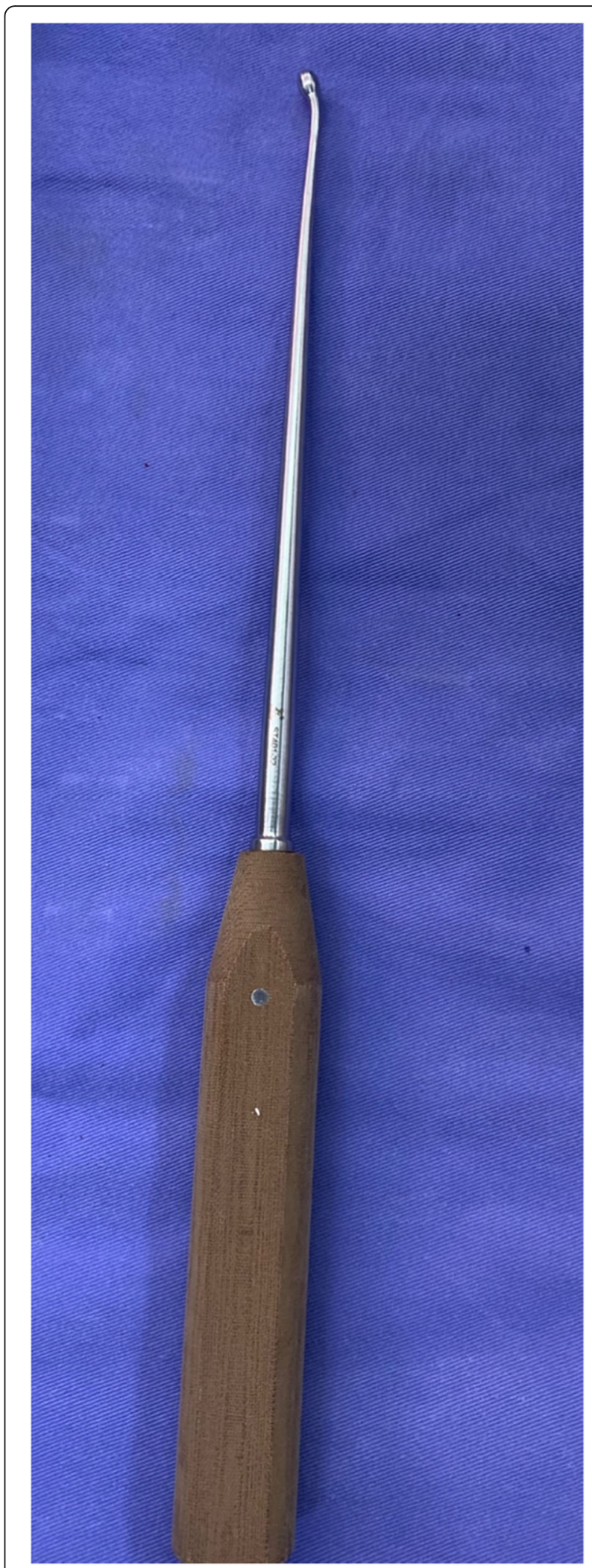

Fig. 1 Illustration of an independently developed reduction facility 

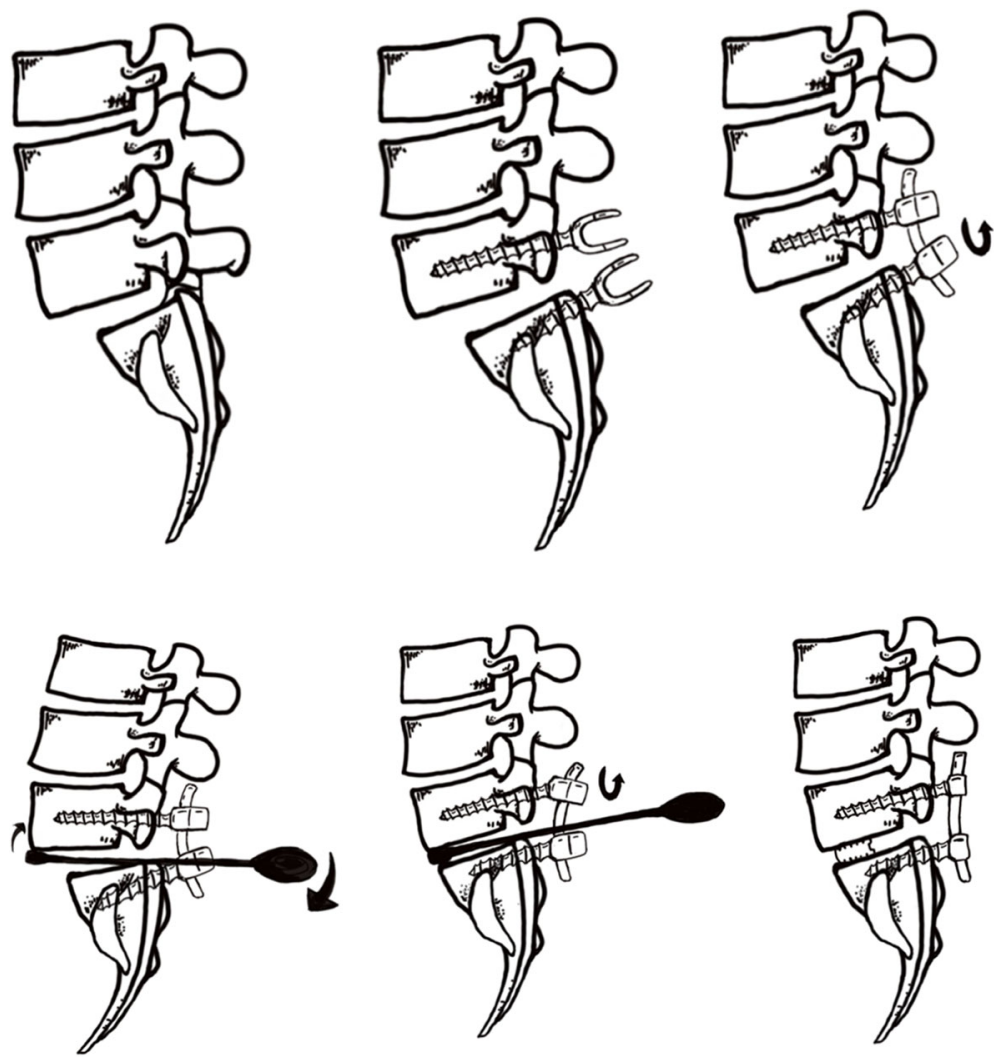

Fig. 2 Reduction process of a slipped vertebrae. a, Forward slippage of $L 5 ; \mathbf{b}$, Pedicle screws were placed at both vertebra of the slipped levels; $\mathbf{c}$, The nerve roots were decompressed before reduction. After removal of the disk tissues and endplate preparation, a rod was placed unilaterally and the pedicle screw of the lower vertebrae was locked; $\mathbf{d}$, A lever repositioner was placed at the anterior rim of the slipped vertebrae under fluoroscopy; e, With the lower vertebrae as the lever fulcrum, force was applied to gradually pry the slipped vertebrae upward; $\mathbf{f}$, The pedicle screws of the slipped vertebrae were locked. Then, an addition rod was placed and all screws were locked. The extent of slip reduction was verified with fluoroscopy. After reduction, the interspace was packed with autologous bone graft material and an appropriate cage filled with bone was inserted into the disc space

$\mathrm{SP}<25 \%)$ and 44 had grade II $(25 \%<\mathrm{SP}<50 \%)$. Of all patients, 18 had lumbar degenerative scoliosis with an average Cobb angle of $17.6^{\circ}$. The distribution of fusion levels was: 1 segment $(48,33.8 \%), 2$ segments (59, $41.5 \%), 3$ segments $(18,12.7 \%)$, and $>3$ segments (17, $12.0 \%)$. The average number of fused segments was 2.32 .

\section{Clinical outcomes}

Comparisons of clinical and radiological parameters at different time points are shown in Table 3. The clinical parameters of VAS $_{\text {back}}$, VAS leg, ODI, and SF-36 had significantly improved at both follow-ups after surgery $(p<$ 0.001). There were no statistical differences in clinical parameters from 1 month after surgery to the final follow-up $(p>0.05)$.

\section{Radiological outcomes}

Slippage reduction had significantly improved at 1 month after surgery $(p<0.001)$ (Table 3$)$. Slip correction was $70.29 \%$ immediately after surgery. There was no significant difference in the mean SP at 1 month after surgery vs. the final follow-up ( $p=0.452)$, demonstrating no significant correction loss after surgery. SA significantly increased after surgery and was well maintained at the final follow-up (Table 3). LL, on the other hand, was not affected by surgery. To minimize the effect of fused segments on LL, patients with a single fused segment were included for analysis, but there was no significant difference between pre-and post-operative LL (Table 3). No significant correction loss was observed in SA and LL. At the final follow-up, complete fusion (grade I) was achieved in 121 patients $(85.2 \%)$ and partial fusion (grade I I) in 21 (14.8\%).

\section{Complications}

Revision surgery was performed in one patient because of cage malposition during hospitalization. Screw loosening was observed in $3(2.11 \%)$ cases (one at 3 months after surgery and the other two at 6 months), all of which occurred at the S1 vertebrae. None of these 


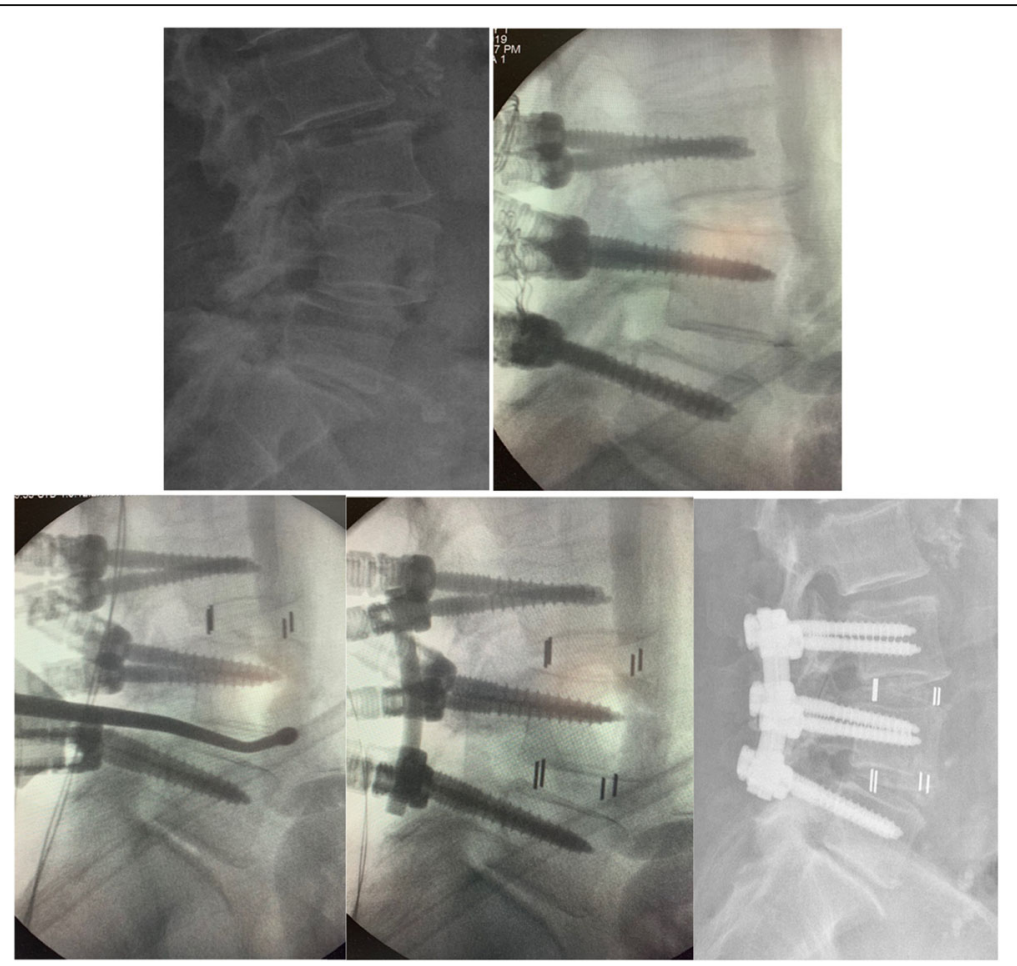

Fig. 3 Female patient, 74 years old, diagnosed of lumbar degenerative spondylolisthesis and lumbar stenosis ( $L 3 / 4$ and $L 4 / 5)$. a, Forward slippage of $L 4 ; \mathbf{b}$, Pedicle screws were placed from $L 3$ to $L 5 ; \mathbf{c}$, After decompression of both levels and cage insertion at $L 3 / 4$, a lever repositioner was placed at the anterior rim of the slipped vertebrae under fluoroscopy; $\mathbf{d}$, A rod was placed unilaterally and the pedicle screws of $L 3$ and $L 5$ were locked. After $L 4$ was pried upward, the pedicle screw of $L 4$ was locked and cage was then inserted; e, Postoperative X-ray showed satisfactory reduction of $L 4$

patients complained of back or leg pain and all had achieved partial fusion at the final follow-up. Two patients developed deep wound infections and underwent

Table 2 Demographic Data and Intraoperative Characteristics of All Patients

\begin{tabular}{ll}
\hline Variables & Data \\
\hline Age & $72.8 \pm 6.91$ \\
Gender(female/male) & $104 / 38$ \\
Mean follow-up (month) & $25.42 \pm 8.31$ \\
Smoking (yes/no) & $18 / 124$ \\
Alcohol (yes/no) & $10 / 132$ \\
Body mass index (BMI) & $26.12 \pm 3.1$ \\
Bone mineral density (g/cm²) & $0.821 \pm 0.164$ \\
Number of comorbidities & \\
$\quad<3$ & 121 \\
$\quad \geq 3$ & 21 \\
Meyerding grade, l/ll & $98 / 44$ \\
Surgical time (min) & $183 \pm 91.5$ \\
Blood loss (ml) & $431 \pm 426.7$ \\
Hospital stay (day) & $15.62 \pm 6.59$ \\
\hline
\end{tabular}

Data are presented as the mean \pm SD debridement without removing the implant. No nerve root injury was observed during reduction. Deep vein thrombosis occurred in one patient, while pneumonia was observed in two. No adjacent segment disease was observed at the final follow-up.

\section{Discussion}

Since first described by Jenkins et al. [23] in 1936, surgical reduction for the treatment of lumbar spondylolisthesis has remained controversial [24, 25]. In Kawakami's study, severe low back pain and lower recovery rate were observed in patients after in situ fusion compared with those in patients with reduction [24]. Two comparative studies on the clinical results of patients with and without reduction failed to find any significant difference $[26,27]$. However, both studies included relatively small numbers of patients and the heterogeneity made it impossible to draw a firm conclusion. Although slip reduction remains controversial, restoration of segmental alignment and sagittal balance is still appealing and may be beneficial to limit degeneration of the adjacent segment degeneration in the long-term follow-up [24].

Multiple techniques have been described for the reduction of spondylolisthesis. For example, Magerl et al. [28] used external transpedicular fixation to provide 
Table 3 Comparisons of Clinical and Radiological Parameters Preoperatively and Postoperatively

\begin{tabular}{lllll}
\hline Parameters & Preoperatively & 1 month postoperatively & Final follow-up & $p$ value \\
\hline VAS $_{\text {back }}$ & $7.3 \pm 2.1$ & $1.8 \pm 0.9$ & $2.2 \pm 1.5$ & $<0.001^{a}$ \\
VAS leg $^{\text {a }}$ & $6.8 \pm 1.9$ & $1.2 \pm 0.6$ & $1.4 \pm 1.1$ & $<0.001^{\text {a }}$ \\
ODI (\%) & $63.1 \pm 21.3$ & $20.4 \pm 9.1$ & $15.6 \pm 6.8$ & $<0.001^{\text {a }}$ \\
SF-36(\%) & $44.3 \pm 16.7$ & $65.7 \pm 17.4$ & $71.3 \pm 15.8$ & $<0.001^{\text {a }}$ \\
SP $(\%)$ & $18.31 \pm 9.38$ & $5.44 \pm 2.66$ & $6.39 \pm 2.78$ & $<0.001^{\text {a }}$ \\
SA $\left(^{\circ}\right)$ & $5.89 \pm 4.87$ & $9.47 \pm 4.08$ & $9.18 \pm 4.33$ & $<0.001^{\text {a }}$ \\
LL $\left(^{\circ}\right)$ & $44.06 \pm 12.69$ & $45.53 \pm 11.16$ & $44.83 \pm 11.24$ & 0.1573 \\
LLSS $\left.^{(}\right)$ & $45.47 \pm 14.45$ & $46.07 \pm 13.32$ & $45.65 \pm 13.89$ & 0.6738 \\
\hline
\end{tabular}

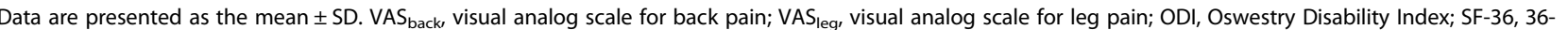
Item Short Form Health Survey; SP, slip percentage; SA, slip angle, LL, lumbar lordosis; LLss, lumbar lordosis in patients with single segment fused. ${ }^{a}$ means preoperative data was different from the data at 1 month postoperatively

distraction and compression forces in the reduction process. But, there was a high rate of pin site complications requiring multiple surgeries, thus this technique is seldom used. Ilharreborde et al. [29] applied a cantilever maneuver to obtain reduction and create lordosis at the spondylolisthetic level and Ruf et al. [30] proposed the temporary use of transpedicular reduction screws as a means to combine distraction and pulling strength during reduction. Other reduction methods, including traction, transsacral interbody fusion technique, and minimally invasive lumbar interbody fusion, have also been used [31-33].

The techniques mentioned above meet two requirements: distraction of the disc space and pulling of the slipped vertebrae. Theoretically, distraction and pulling strength via pedicle screws required adequate contact force between the instrumentation and bone. But, in elderly patients with LDS, poor bone quality may cause greater risks of instrumentation failure $[15,16]$.

To minimize the risks of implant-related complications during reduction, we adopted a new lever reduction technique combined with transforaminal lumbar interbody fusion for the surgical treatment of elderly LDS patients. After removing the disc and decompression of the nerve roots, a lever reduction assembly was placed at the anterior rim of the slipped vertebrae. Using the lower vertebrae as the lever fulcrum, force was applied to gradually pry the slipped vertebrae up and then lock the pedicle screws of the slipped vertebrae. During the reduction process, the force applied to the lever repositioner could be decomposed to horizontal and vertical stress, which served as distraction and pulling force, respectively. Since the pulling force is essential for reduction, the direction of the force applied to the lever repositioner will affect reduction (Fig. 4). Furthermore, lumbar lordosis, slip angle, slip degree, and disc space may affect the correction rate.

The reason for choosing the anterior rim as the prying point is based on the anatomic and biomechanical characteristics of the lumbar endplates. Peripheral regions have increased endplate thickness and bone density, as compared to the center of the endplate [34, 35]. A study by Liu et al. [36] found that the strength and stiffness was greater by $17 \%$ in the outer regions, as compared to the inner regions of the lumbar endplate. Although the anterior rim can provide reduction forces, care must be taken and the whole process should be completed under fluoroscopy. No intraoperative screw loosening was observed even though injury to the endplate could not be avoided.

In the current study, the average age of patients was $72.8 \pm 6.91$ years and $76 \%$ had osteopenia or osteoporosis. The complication rate in these elderly patients is relatively high. In a prospective study [15], pedicle screws were pulled out intraoperatively in two elderly patients $(5.6 \%)$ using traditional reduction method and the complication rate was $22.2 \%$. Another study reported a correction rate of $30.1 \%$ and a fusion rate of $64 \%$ on CT-scan for patients with low-grade spondylolisthesis after 1 year's follow-up [22]. Okuda et al. reported a complication rate of $16 \%$ and a correction rate of $58.3 \%$ in elderly patients with a nonunion rate of 4\% [37].

Compared with patients undergoing traditional reduction method, patients in this study had lower complication rate. Though most patients had poor bone quality, the clinical outcomes were satisfactory and a mean correction rate of $70.29 \%$ was achieved using this technique. No intraoperative screw loosening or other implant failure was observed, and all patients achieved complete or partial fusion at a mean follow-up of $25.42 \pm 8.31$ months.

The correction of segmental kyphosis and spinal alignment is also very important. The mean slip angle was $5.89 \pm 4.87^{\circ}$, which increased to $9.47 \pm 4.08^{\circ}$ at 1 month after surgery and $9.18 \pm 4.33^{\circ}$ at the final follow-up. LL, on the other hand, was not affected by surgery. To minimize the effect of fused segments on LL, patients with a single fused segment were included and we also found no significant difference between pre-and post- 

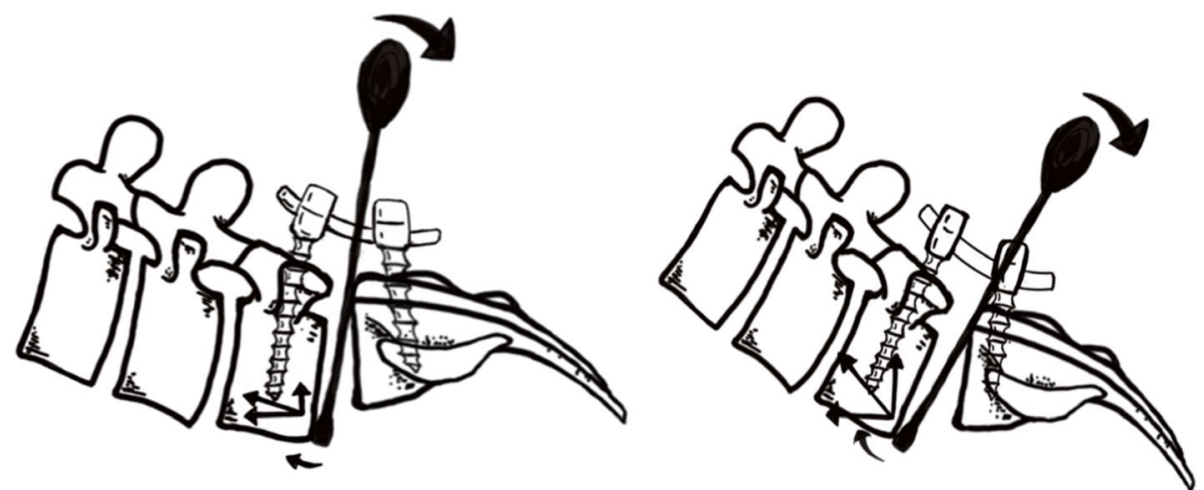

Fig. 4 a The lever repositioner is placed more vertical leading to small decomposed force in the vertical direction (pulling strength). b The lever repositioner is placed more horizontal leading to large decomposed force in the vertical direction

operative LL. The correction loss was relatively small and resulted no statistical difference. With this technique, restoration of alignment is achieved via reduction of slippage and insertion of an intervertebral cage to avoid the potential risks of nerve root compression and screw loosening due to posterior compression.

One of the benefits of reduction is a greater fusion rate. In this study, all patients achieved complete or partial fusion at the final follow-up. Many studies have used plain radiographs to assess fusion integrity, including one that classified fusion as motion of less than $5^{\circ}$ on dynamic lateral radiographs [38]. As noted by Boden et al. [39], the presence of residual segmental motion generally suggests non-union, although a lack of motion does not necessarily imply spinal fusion. Other authors have also suggested that the ability to demonstrate spinal fusion is limited on plain radiographs $[40,41]$. To better evaluate the fusion rate, we used the fusion classification proposed by Tan et al. [21] on CT scan, which reflected the actual fusion status after surgery.

This study had some limitations. First, this is a prospective study with small number of patients and relatively short follow-up time. Secondly, this is not a comparative study lacking a control group with decompression and fusion without reduction. Hence, future studies are needed to compare this technique with in situ fusion and other reduction techniques.

\section{Conclusion}

This new lever reduction technique combined with traditional elevating-pull reduction technique for the reduction of elderly patients with LDS is safe and effective. Satisfactory correction and fusion rates were achieved with acceptable correction loss and reduction-related complications. Further comparative studies between this technique and other reduction methods are needed in the future.

\section{Abbreviations}

LDS: Lumbar degenerative spondylolisthesis; LL: Lumbar lordosis;

ODI: Oswestry Disability Index; SA: Slip angle; SF-36: 36-Item Short Form Health Survey; SP: Slip percentage; TLIF: Transforaminal lumbar interbody fusion; VAS: Visual analog scale

\section{Acknowledgements \\ We thank International Science Editing (http://www. \\ internationalscienceediting.com) for editing this manuscript.}

\section{Authors' contributions}

KC analyzed and interpreted the patient data and wrote the paper. WW analyzed the data and did the follow-ups. LS designed the study and revised the paper. DJ performed the statistical analysis. LX analyzed the data. SX did the follow-ups and collected the data. All authors have read and approved the manuscript.

\section{Funding}

This work was supported by the National Natural Science Foundation of China [grant numbers 81672201 and 81871794], which covered the followup cost.

\section{Availability of data and materials}

The datasets used and/or analyzed during the current study are stored in our hospital and are available from the corresponding author on reasonable resquest.

\section{Ethics approval and consent to participate}

This study was approved by the Ethical committee of Beijing Xuanwu Hospital. Each participant gave written, informed consent to participate.

\section{Consent for publication}

Consent for publish potentially-identifying information of patients was obtained written.

\section{Competing interests}

The authors declare that they have no competing interests.

Received: 19 November 2019 Accepted: 24 December 2019 Published online: 07 January 2020

\section{References}

1. Newman PH, Stone KH. The etiology of spondylolisthesis. J Bone Joint Surg Br. 1963;45(1):39-59.

2. Matz PG, Meagher RJ, Lamer T, Tontz WL Jr, Annaswamy TM, Cassidy RC, Cho CH, Dougherty P, Easa JE, Enix DE, Gunnoe BA, Jallo J, Julien TD, Maserati MB, Nucci RC, O'Toole JE, Rosolowski K, Sembrano JN, Villavicencio AT, Witt JP. Guideline summary review: an evidence-based clinical guideline for the diagnosis and treatment of degenerative lumbar spondylolisthesis. Spine J. 2016;16(3):439-48. 
3. Wiltse LL, Newman PH, Macnab I. Classification of spondylolisis and spondylolisthesis. Clin Orthop Relat Res. 1976;117:23-9.

4. Meyerding HW. Spondylolisthesis. J Bone Joint Surg. 1931;13:39-48.

5. Kalichman L, Hunter DJ. Diagnosis and conservative management of degenerative lumbar spondylolisthesis. Eur Spine J. 2008;17:327-35.

6. Sengupta DK, Herkowitz HN. Lumbar spinal stenosis. Treatment strategies and indications for surgery. Orthop Clin North Am. 2003;34:281-95.

7. Weinstein JN, Lurie JD, Tosteson TD, Hanscom B, Tosteson AN, Blood EA, et al. Surgical versus nonsurgical treatment for lumbar degenerative spondylolisthesis. N Engl J Med. 2007;356:2257-70.

8. Weinstein JN, Lurie JD, Tosteson TD, Zhao W, Blood EA, Tosteson AN, et al. Surgical compared with nonoperative treatment for lumbar degenerative spondylolisthesis. Four-year results in the spine patient outcomes research trial (SPORT) randomized and observational cohorts. J Bone Joint Surg Am. 2009:91:1295-304.

9. Transfeldt EE, Mehbod AA. Evidence-based medicine analysis of isthmic spondylolisthesis treatment including reduction versus fusion in situ for high-grade slips. Spine. 2007;32(19):S126-9.

10. Anonymous: Diagnosis and Treatment of Degenerative Lumbar Spondylolisthesis, in Clinical Guidelines for Multidisciplinary Spine Care. Burr Ridge, IL: North American Spine Society, 2008.

11. Verbiest $\mathrm{H}$. The treatment of lumbar spondyloptosis or impending lumbar spondyloptosis accompanied by neurologic deficit and/or neurogenic intermittent claudication. Spine. 1979;4(1):68-77.

12. Frennered AK, Danielson BI, Nachemson AL, Nordwall AB. Midterm followup of young patients fused in situ for spondylolisthesis. Spine. 1991;16(4): 409-16.

13. Vail D, Azad TD, O'Connell C, Han SS, Veeravagu A, Ratliff JK. Postoperative opioid use, complications, and costs in surgical Management of Lumbar Spondylolisthesis. Spine (Phila Pa 1976). 2018 Aug 1;43(15):1080-8.

14. Fehlings $M G$, Rabin D. Surgical complications in adult spondylolisthesis. J Neurosurg Spine. 2010 Nov;13(5):587-588; discussion 588.

15. Lian X, Hou T, Xu J, Zeng B, ZhaoJ LX, Zhao C, Li H. Posterior lumbar interbody fusion for aged patients with degenerative spondylolisthesis: is intentional surgical reduction essential? Spine J. 2013;13:1183-9.

16. Lian XF, Hou TS, XU JG, Zeng BF, Zhao J, Liu XK, Yang EZ, Zhao C. Single segment of posterior lumbar interbody fusion for adult isthmic spondylolisthesis: reduction or fusion in situ. Eur Spine J. 2014;23:172-9.

17. Bai X, Chen J, Liu L, Li X, Wu Y, Wang D, Ruan D. Is reduction better than arthrodesis in situ in surgical management of low-grade spondylolisthesis? A system review and meta analysis. Eur Spine J. 2017 Mar;26(3):606-18.

18. Genant HK, Cooper C, Poor G, et al. Interim report and recommendations of the World Health Organization task-force for osteoporosis. Osteoporos Int. 1999:10:259-64.

19. Taillard W. Spondylolisthesis in children and adolescents. Acta Orthop Scand. 1954;24:115-44.

20. M HW. Spondylolisthesis. Can Med Assoc J. 1932;26:16-8.

21. Tan GH, Goss BG, Thorpe PJ, Williams RP. CT-based classification of long spinal allograft fusion. Eur Spine J. 2007;16(11):1875-81.

22. Hagenmaier HS, Delawi D, Verschoor N, Oner F, van Susante JL. No correlation between slip reduction in low-grade spondylolisthesis or change in neuroforaminal morphology and clinical outcome. BMC Musculoskelet Disord. 2013 Aug 19:14:245.

23. Jenkins JA. Spondylolisthesis. Br J Surg. 1936;24:80-5.

24. Kawakami M, Tamaki T, Ando M, Yamada H, Hashizume H, Yoshida M. Lumbar sagittal balance influences the clinical outcome after decompression and posterolateral spinal fusion for degenerative lumbar spondylolisthesis. Spine (Phila Pa 1976). 2002 Jan 1;27(1):59-64.

25. Schöller K, Alimi M, Cong GT, Christos P, Härtl R. Lumbar spinal stenosis associated with degenerative lumbar Spondylolisthesis: a systematic review and Meta-analysis of secondary fusion rates following open vs minimally invasive decompression. Neurosurg. 2017 Mar 1;80(3):355-67.

26. Audat ZM, Darwish FT, Al Barbarawi MM, Obaidat MM, Haddad WH, Bashaireh KM, Al-Aboosy IA. Surgical management of low-grade isthmic spondylolisthesis; a randomized controlled study of the surgical fixation with and without reduction. Scoliosis. 2011;6:14.

27. Benli IT, Cicek H, Kaya A. Comparison of sagittal plane realignment and reduction with posterior instrumentation in developmental low or high dysplastic spondylolisthesis. Kobe J Med Sci. 2006;52:151-69.

28. Magerl FP. Stabilization of the lower thoracic and lumbar spine with external skeletal fixation. Clin Orthop Relat Res. 1984;189:125-41.
29. Iharreborde B, Fitoussi F, Morel E, et al. Jackson's intrasacral fixation in the management of high-grade isthmic spondylolisthesis. J Pediatr Orthop B. 2007;16(1):16-8.

30. Ruf $\mathrm{M}$, Koch $\mathrm{H}$, Melcher RP, et al. Anatomic reduction and monosegmental fusion in high-grade developmental spondylolisthesis. Spine (Phila Pa 1976). 2006;31(3):269-74.

31. Hart RA, Domes CM, Goodwin B, D'Amato CR, Yoo JU, Turker RJ, Halsey MF. High-grade spondylolisthesis treated using a modified Bohlman technique: results among multiple surgeons. J Neurosurg Spine. 2014 May;20(5):523-30

32. Bouras T, Korovessis P. Management of spondylolysis and low-grade spondylolisthesis in fine athletes. A comprehensive review. Eur J Orthop Surg Traumatol. 2015;25(Suppl 1):S167-75.

33. Isaacs RE, Sembrano JN, Tohmeh AG, SOLAS Degenerative Study Group. Two-Year Comparative Outcomes of MIS Lateral and MIS Transforaminal Interbody Fusion in the Treatment of Degenerative Spondylolisthesis: Part II: Radiographic Findings. Spine (Phila Pa 1976). 2016 Apr;41(Suppl 8):S133-44.

34. Hou Y, Luo Z. A study on the structural properties of the lumbar endplate: histological structure, the effect of bone density, and spinal level. Spine (Phila Pa 1976). 2009 May 20;34(12):E427-33.

35. Zhao FD, Pollintine P, Hole BD, Adams MA, Dolan P. Vertebral fractures usually affect the cranial endplate because it is thinner and supported by less-dense trabecular bone. Bone. 2009:44(2):372-9.

36. Liu J, Hao L, Suyou L, Shan Z, Maiwulanjiang M, Li S, Wang C, Fan S, Zhao F. Biomechanical properties of lumbar endplates and their correlation with MRI findings of lumbar degeneration. J Biomech. 2016 Feb 29:49(4):586-93.

37. Okuda S, Oda T, Miyauchi A, et al. Surgical outcomes of posterior lumbar interbody fusion in elderly patients. J Bone Joint Surg Am. 2006;88:2714-20.

38. Pearcy M, Burrough S. Assessment of bony union after interbody fusion of teh lumbar spine using a biplanar radio- graphic technique. J Bone Joint Surg Br. 1982;64-B:228-322.

39. McAfee PC, Boden SD, Brantigan JW, Fraser RD, Kuslich SD, Oxland TR, Panjabi MM, Ray CD, Zdeblick TA. Sympo- sium. A critical discrepancy-a criteria of successful arthrodesis following interbody spinal fusions. Spine. 2001;26:320-34.

40. Tuli SK, Chen P, Eichler ME, Woodard EJ. Reliability of radiologic assessment of fusion: cervical fibular allograft model. Spine. 2004;29:856-60.

41. Santos ERG, Goss DG, Morcom RK, Fraser RD. Radio- logic assessment of interbody fusion using carbon fiber cages. Spine. 2003;28:997-1001.

\section{Publisher's Note}

Springer Nature remains neutral with regard to jurisdictional claims in published maps and institutional affiliations.
Ready to submit your research? Choose BMC and benefit from:
- fast, convenient online submission
- thorough peer review by experienced researchers in your field
- rapid publication on acceptance
- support for research data, including large and complex data types
- gold Open Access which fosters wider collaboration and increased citations
- maximum visibility for your research: over $100 \mathrm{M}$ website views per year
At $\mathrm{BMC}$, research is always in progress. 